\title{
Processo Saúde/Doença e Complexidade em Epidemiologia
}

\section{Health/Disease Process and Complexity in Epidemiology}

\author{
Fermin R. Schramm' \\ Luis David Castiel ${ }^{2}$
}

SCHRAMM, F. R. \& CASTIEL, L. D. Health/Disease Process and Complexity in Epidemiology. Cad. Sauide Públ., Rio de Janeiro, 8 (4): 379-390, oct/dec, 1992.

The use of the idea of Complexity in Epidemiology is an approach to point out either an internal disciplinary crisis, resulting from shortcomings in its conceptual instruments (theories, models) regarding health's concrete reality, or a crisis in terms of the broader cultural context (paradigms, epistemic framework, Zeitgeist, Weltanschauung) in which health issues are necessarily inserted. Although those two approaches are pertinent from a systemic and environmental standpoint, their disjunction is insufficient in dealing with the main contemporary health challenges that affect individuals, populations and the biosphere. Complexity consists of a point of view that appears to overcome this obstacle. On the one hand, it stresses the reductionism of dichotomous visions that shaped the Modern Age, generally unable to focus on a living universe made up of relations and the emergence of new properties, when we move from one level of organization to another. On the other hand, ways of dealing with living beings' interactive processes are presented. A dynamic, historical and evolutive perspective is presented as a way of looking upon the crisis in Epidemiology as a sign, pointing out the need to conceive a complex approach towards its practical discursive instruments in order to devise more suitable patterns for the Health/Disease process..

Keywords: Epidemiology, Epistemology, Complexity

\section{INTRODUÇÃO}

As considerações aqui apresentadas procedem de um duplo ponto de vista "construtivista". O primeiro, interno, considera a dita "crise de identidade" da Epidemiologia (Almeida-Filho, 1990) como um "efeito" do processo em que a multiplicação de modelos de análise do "fenômeno" complexo da saúde em populações diferencia o próprio campo global e tradicional da Epidemiologia - tido, até então, como unitário - em especializações locais e setoriais. Isto ocorreria de tal modo que permitiria supor a existência de várias epidemiologias, tornando

\footnotetext{
${ }^{1}$ Departamento de Ciências Sociais da Escola Nacional de Saúde Püblica. Rua Leopoldo Bulhöes, 1480, 98 andar, 21041-210, Rio de Janeiro, RJ, Brasil.

${ }^{2}$ Departamento de Epidemiologia e Métodos Quantitativos em Saude da Escola Nacional de Saude Pública. Rua Leopoldo Bulhões, 1480, $8^{\circ}$ andar, 21041 210, Rio de Janeiro, RJ, Brasil.
}

cada vez mais problemática uma visão unificada e compreensiva - isto é, global - dos fatos epidemiológicos. Deste ponto de vista, a "crise" seria, em primeiro lugar, o efeito de um crescimento interno ao saber epidemiológico, devido à construção de vários modelos "locais" e à emergência de novos problemas que devem coexistir com os antigos. Ou seja, tratar-se-ia de uma crise de complexificação do campo da Saúde Coletiva, que, por um lado, precisaria de um aprofundamento das análises específicas (para escapar da generalidade, que não dá conta dos casos concretos), assim como do estreitamento das relações interdisciplinares (para evitar a parcialidade da modelização). Em suma, questões que dizem respeito à complexidade e à interdisciplinaridade seriam as características internas desta crise de identidade da Epidemiologia.

O segundo ponto de vista, externo, mas vinculado ao primeiro pelo mesmo processo 
construtivo, situa a Epidemiologia no interior das transformações que se operam no próprio conjunto das ciências e dos discursos que acompanham tais transformações. As ciências percebem-se, atualmente, como fazendo parte de uma "era de transição", o que, portanto, implica o reconhecimento de crises, isto é, momentos decisórios que produzem os novos objetos teóricos, a reconceituação e a reterritorialização dos antigos, dentro de um novo "quadro epistêmico" (Piaget \& Garcia, 1987).

No interior deste novo contexto teórico, o mundo apresenta-se cada vez mais como estando inserido em um universo "unidual", no qual encontram-se fenômenos tanto "determinísticos" quanto "estocásticos", tanto "reversíveis" quanto "irreversíveis". Neste mundo, que desde a era moderna é concebido como aberto, "evolução" e "pluralismo" tornar-se-iam as palavras fundamentais (Nicolis \& Prigogine, 1991).

Conforme esses dois pontos de vista - que são, na realidade, dois aspectos do mesmo processo de construção do conhecimento,- 0 lugar discursivo em que nos situamos é do tipo interfacial, ou seja, na fronteira entre "construção interna" - ou disciplinar - do campo epidemiológico e "construção externa" - ou contextual. Em suma, entre ponto de vista local e ponto de vista global. Esta fronteira entre sistema e contexto, portanto, é também uma região de contato e situa-se no limiar que abre (segundo uma célebre expressão, de 1934, do epistemólogo Gaston Bachelard) para o "novo espirito científico" (Bachelard, 1985), ou seja, para o quadro da revolução científica específica do século XX. Hoje em dia, costuma-se chamar este "novo espírito científico" de ponto de vista da complexidade, entendendo-se, com isso, de maneira bastante intuitiva, um ponto de vista relacional e dinâmico, em oposição à tradição dicotômica e estática cartesiana da época moderna.

Contudo, nesta "era de transição", o ponto de vista complexo não pertence somente à prática e à teoria da ciência. Ele afeta também a "humanitude" do homem, isto é, as várias dimensões (como a estética, a ética, a política) da "contribuição humana para o universo (...), que não fazia parte da contribuição da natureza" (Jacquard, 1987: 177), vindo a se constituir, desta maneira, em um verdadeiro novo Zeitgeist da nossa contemporaneidade, além de ser, evidentemente, $o$ indício significativo da construção de uma nova Weltanschauung. Assim, uma nova maneira de pensar dar-se-ja junto com uma nova maneira de sentir.

Segundo a epistemóloga Isabelle Stengers, hoje a "complexidade" é uma noção intuitiva que pertence ao nosso vocabulário cotidiano. Para esta autora, "complexidade" seria muitas vezes utilizada como sinônimo de "complicação", dando origem à confusão entre "propriedades objetivas", que pertencem aos sistemas complexos, e "propriedades subjetivas", que são atribuídas a sistemas cuja complicação dependeria, de fato, da limitação dos nossos pontos de vista (Stengers, 1990). No campo das ciências, a idéia de complexidade aparece também cada vez mais como tendo se alastrado dos territórios de origem da sua utilização como as ciências biológicas e as ciências humanas e sociais - para as ciências "duras", como a física. Hoje, as próprias leis fundamentais do universo deveriam ser consideradas complexas (Nicolis \& Prigogine, 1991). Como afirma Prigogine, "Do ponto de vista da ciência contemporânea (...), as leis da biologia, assim como aquelas das sociedades humanas, exprimem o conteúdo de leis que vão além do estreito âmbito da biologia e das sociedades humanas" (Prigogine, 1987: 191). O fato relevante é que este novo olhar põe em crise antigas dicotomias, como aquela entre natureza e cultura, conferindo à própria natureza uma dimensão essencialmente histórica, vinculando-a à "flecha do tempo", isto é, a "bifurcações", a "rupturas de simetria", ao acaso. Nesta concepção fundamentalmente não-dicotômica, o próprio real aparece como uma vinculação entre ordem e desordem, como gerador da variedade de formas e estruturas que nos rodeiam, mas unificado pelo tempo e pela história.

Do duplo ponto de vista construtivista aqui adotado, apreender o real significa construir modelos e confrontá-los com as observações. Nos processos de conhecimento, a mente examina o ambiente; classifica as observações por meio de hipóteses, esquemas e modelos, tentando integrá-los no já adquirido e tirando conclusões parciais que, se forem suficientemente estruturadas e integráveis, permitirão conclusões mais gerais e, eventualmente, a formulação de 
uma teoria sobre uma classe de fenômenos. Neste processo - que é uma verdadeira construção do real (Piaget, 1937) -, a mente procede de duas maneiras complementares: por "computação lógica" (que permite a "distinção") e por "associação analógica" (que permite a "significação"). Para Edgar Morin, estas duas operações mentais constituem as duas faces inseparáveis das operações da mente - a do pensamento lógico-simbólico e a do pensamento analógico-mítico-arquetípico. A apreensão do real seria feita por meio destas duas operações, que são operações distinguíveis, mas inseridas em uma estruturação em anel que permite a "retroação" (feedback) de uma sobre a outra, isto é, a passagem recíproca de informação de uma para a outra. Este fato permitiria o aumento de informação e a complexificação do sistema (Morin, 1986). Dito de forma mais precisa, o processo desenvolve-se em duas etapas sucessivas. Na primeira, ele procede por analogia, estabelecendo relações entre a observação do novo e a memória do antigo (que funciona, então, como um sistema de referência), construindo um modelo que seja o mais adequado possível à experiência e que, desde então, funcionaria como um novo sistema de referência (ou "modelo padrão"). Em seguida, tenta-se ir além da analogia para reconhecer, dentro do quadro do modelo adotado, as especificidades de cada novo problema, incorporando-as à descrição. Da confrontação entre o novo e o antigo nasce a possibilidade de previsão e, quando existe um acordo, têm-se as condições suficientes para formular uma teoria, ou seja, "o meio para dominar a complexidade" (Nicolis \& Prigogine, 1991: 251).

Nos sistemas vivos, existem, pois, diferentes graus de complexidade, dependendo da variedade de comportamentos perante as variações do seu ambiente, isto é, do número de escolhas possíveis para a auto-organização do sistema. Sistema e ambiente vinculam-se na troca de matéria, energia e informação. Tais trocas são máximas nos sistemas dinâmicos, como as sociedades humanas, que são tipos de sistemas entre os mais complexos. Com efeito, as sociedades humanas, contrariamente a outros sistemas dinâmicos e complexos (que não participam da construção da "humanitude"), são históricas stricto sensu, desenvolvem projetos e satisfazem desejos, criando, assim, novos vínculos entre sistema e ambiente, ou seja, dando origem a uma nova dinâmica do conjunto sistema-ambiente, que, por sua vez, cria uma nova complexidade. Desta maneira, a capacidade de controle, assim como de previsão da evolução do conjunto, diminui conforme o aumento da complexidade, precisando de mais controle, do processamento informacional das trocas por meio de modelos com maior desempenho, de "diálogos" inéditos entre pontos de vista diferentes. Ou seja, torna-se necessário o aprofundamento da análise local por meio de modelos informativamente mais performantes ("redutores" da complexidade) e a integração das várias análises locais em uma compreensão global consistente ou em uma teoria.

Então, se admitirmos que a Epidemiologia "construiu-se, historicamente, como uma disciplina heterogênea em seus objetivos, métodos e práticas [e se] é a interdisciplinaridade [que constitui] a característica mais marcante da ciência epidemiológica" (Possas, 1991: 316), esta parece ter que inserir-se em um novo quadro epistêmico da complexidade que permita não somente fundar a nova aliança interdisciplinar entre ciências naturais e ciências humanas (Prigogine \& Stengers, 1979), mas também integrar saúde e doença na realidade da vida concebida como sendo, ao mesmo tempo, natural e sócio-cultural, individual e coletiva.

\section{A EPIDEMIOLOGIA COMO INSTRUMENTO DE CONSTRUÇÃO DO REAL}

No trabalho "Avances Metodológicos en Epidemiologia", apresentado no I Congresso Brasileiro de Epidemiologia, Castellanos faz uma tentativa de utilização da idéia de complexidade no estudo dos processos de saúde-doença nas populações. Diz ele: "(...) a situação de saúde de um grupo de população inclui, em qualquer momento, fenômenos que se evidenciam como diferenças (variaçōes) na freqüencia ou intensidade, ao nivel de individuos; fenômenos que se evidenciam como diferenças entre grupos; e fenômenos que se evidenciam como diferenças entre formaçōes sociais" (Castellanos, 1990: 204). Para este autor, haveria, desta 
forma, uma complexidade originária da estrutura da situação de saúde que englobaria diversas dimensões da realidade e que seria, portanto, objetivável. Sua abordagem conduz ao privilegiamento da idéia de complexidade aplicada a determinantes ao nível do Estado, paralelamente à complexidade "de processo". Isto implicaria uma postura de sustentação de uma práxis por parte dos epidemiológos, que "nāo podem renunciar ao estudo da situaçāo de saúde de diferentes grupos de população sem que isto signifique um sacrificio da possibilidade de mobilização de recursos e de participar no processo decisório dos atores sociais" (Castellanos, 1990: 205). Apesar de sugerir uma obrigatória "militância" por parte do epidemiologista ao desempenhar seu papel social, o que daria margem a uma importante discussão, não é este o objetivo deste trabalho. Neste ponto, importa enfatizar a dimensão heurística encontrada no desenvolvimento de Castellanos.

No intuito de melhor esclarecer este aspecto, é preciso situar a discussão sob dois pontos de vista: o primeiro, diacrônico e o segundo, sincrônico. Do ponto de vista diacrônico, vale a referência à tipologia quanto à evolução da Epidemiologia em três grandes periodos, apresentada pelo Prof. Rodrigues da Silva:

" Epidemiologia da constituição pestilencial e dos miasmas: relacionada ds teorias pré-pasteurianas, a partir da primeira metade do século XIX;

- Epidemiologia dos modos de transmissão: coincidente com o inicio da era bacteriologica, responsável pelo estudo das doenças infecto-contagiosas, desde o final do século passado até os anos 50;

- Epidemiologia dos fatores de risco: cujo objeto principal de estudo são as doenças crônico-degenerativas, tendo-se desenvolvido até os dias atuais" (Rodrigues da Silva, 1990: 111).

Segundo Rodrigues da Silva, é possivel localizar correntes explicativas alternativas à predominância das teorias hegemônicas. Levando isto em consideração, destaca o papel da chamada Epidemiologia Social como teoria nãohegemônica que se antepôs à Epidemiologia dos fatores de risco.
Por outro ângulo, a partir de um ponto de vista sincrônico, o campo investigativo da Epidemiologia dita clássica (dos fatores de risco) está, atualmente, sendo local de conflagrações. Temos, por um lado, a chamada Epidemiologia Social (ou Crítica), na busca de uma configuração mais abrangente e equilibrada nos seus pólos de pesquisa (epistemológico, teórico, morfológico e técnico), de modo a consolidar sua proposta alternativa (e emancipatória) de compreensão dos determinantes do processo saúde-doença em populações concretas, com características históricas e sociais próprias (Gonçalves, 1990). Por outro, num movimento aparentemente mais vigoroso, a denominada Epidemiologia Clínica discute a validade científica do empreendimento epidemiológico, que não se baseia no "paradigma" dos ensaios clínicos controlados (Feinstein, 1989, AlmeidaFilho, 1992).

É importante ressaltar o papel fundamental da Epidemiologia Social em denunciar as reduções (e tendenciosidades) das teorias hegemônicas especialmente a propriedade de equalizar (e, assim, minimizar) as variáveis econômicas e sociais ao mesmo nivel das demais variáveis (de pessoa, tempo e lugar), sem destacar a dimensão histórica na determinação do processo saúde-doença, assim como as abordagens meramente descritivas das relações entre o campo da saúde e o todo social (Garcia, 1983). Por sua vez, a Epidemiologia Social, ao mesmo tempo que ressaltava o papel "determinante" das desigualdades sócio-econômicas no processo de adoecimento das populações (ao ancorar-se numa proposta de deslocamento do pólo teórico positivista para o pólo materialista), viu-se sitiada, por um flanco, pelos questionamentos que atingem os modelos explicativos marxistas e, pelo outro, pelas discussões epistemológicas acerca da crise dos paradigmas na ciência. Uma de suas dificuldades está relacionada ao que Bateson chamou confusão de tipos lógicos (Bateson, 1979): como conceituar as variáveis do nível social e operar com as mesmas e como relacioná-las às variáveis do nivel individual? Isto é, de que modo variáveis consideradas como pertencentes à dimensão macro-social (por exemplo, classe social) teriam nexos causais diretos (ou "determinações") com a ocorrência de agravos específicos à saúde 
detectados ao nível micro-social? Desta forma, o estabelecimento das probabilidades de morbimortalidade conforme os diversos modos de inserção no processo econômico não é suficiente para definir a existência de nexos causais ou determinantes entre os níveis "social" $\mathrm{e}$ "individual" (Possas, 1990). Assim, parece ser necessária uma mediação entre os dois níveis, e, então, a falta de um nível de organização intermediário bem-estabelecido, isto é, com sua identidade teórica definida, nos conduz a considerar que a demarcação de relações de causaefeito entre os níveis citados é insatisfatória. Haverá, quando muito, conexões - mas sem permitir afirmações de causalidade (Sabroza, Comunicação Pessoal, 1991).

Como foi referido anteriormente, a discussão de Castellanos sobre a utilização da idéia de complexidade na Epidemiologia sugere démarches promissoras ao apontar para a "necessidade de assumir a realidade como estruturada em diferentes niveis de organização e complexida$d e "$ e considerar a possibilidade de abordá-la mediante o estabelecimento de niveis intermediários de análise, seja o grupo, a comunidade, a família, através de uma matriz de dados composta por unidades de análise, variáveis e valores de tais variáveis (Castellanos, 1990: 206). Tais niveis intermediários constituiriam o lugar de articulação em que se define a interfacialidade entre saúde/doença, individual/coletivo, biológico/social, sistema/ambiente, isto é, as novas fronteiras prático-discursivas dos atuais problemas epidemiológicos. Fronteiras que são, ao mesmo tempo, regiōes de articulação de problemas e lugares de incerteza da teoria. Esta ordem de questões pode ser exemplificada pelos estudos epidemiológicos sobre o estresse, cujos problemas conceituais e metodológicos ilustram as dificuldades pelas quais passa o campo epidemiológico (Castiel, 1992).

Por outro lado, é preciso desenvolver a teorização subjacente à idéia de "fator de risco". A rigor, ela introduz um atributo de identidade entre o possível e o provável, trazendo o pressuposto de que o provável é quantificável. Tal concepção acentuaria, a princípio, a dimensão preditiva da disciplina. Para isto se concretizar de fato, inclui-se um elemento de homogeneização: os objetos de estudo (via de regra, amostras populacionais) são comparáveis e generalizáveis às populações gerais (desde que sejam seguidos certos critérios "metodológicos" e tomadas algumas precauções). Assim, há a possibilidade de operar-se uma confusão de tipos lógicos, pois se produz um deslocamento do estatuto de "fator de risco" - conforme um "padrão" de exposição achado numa amostra considerada representativa de uma determinada população-alvo (que se situa num tipo lógico) para a população geral (tipo lógico hierarquicamente superior) e, por sua vez, para o nivel individual (tipo lógico inferior), atribuindo-lhe um "risco" (no sentido de ameaça de um dano) de ser atingido pelo efeito em questão, caso haja uma exposição correspondente (Almeida-Filho, 1992). Em suma, na verdade, estes pressupostos oferecem problemas de confusão de tipos lógicos - variáveis localizadas em uma dada dimensão (populacional) talvez não possuam o mesmo comportamento se consideradas ao nível do indivíduo. Em termos epidemiológicos, as causas da incidência de uma doença podem ser distintas das causas da ocorrência do caso individual (Rose, 1984). Além disso, têm-se percebido um emprego da noção de "risco" como uma categoria submetida à crescente medicalização, isto é, uma redução que poderíamos chamar de tipo pragmáticofuncional. Desta forma, o "risco" adquire o estatuto de entidade passível de intervenção e, com isto, geradora do consumo de práticas terapêuticas e preventivas próprias (Almeida Filho, 1992).

Por sua vez, a característica quantificadora, base para a busca de nexos causais (e a conseqüente capacidade de previsão), estimulada pela proliferação de recursos computacionais e de técnicas estatísticas de análise (Susser, 1991), vê-se na contingência de dar conta dos fenômenos de interação e sinergismo entre os possíveis fatores causais (Sabroza, Comunicaçāo Pessoal, 1991). Neste caso, a agregação destes componentes gera a emergência de uma nova "qualidade", com propriedades que ultrapassam as propriedades dos componentes individuais, considerados isoladamente. Teríamos, então, um comportamento "mais complexo", regido por funções não-lineares.

Então, se encararmos a complexidade co no característica dos sistemas auto-organizados, estes deveriam dispor de: redundância - 
repetição de módulos estruturais e funcionais (Bourguignon, 1990), ou, conforme a teoria da informação, um afastamento previsível da aleatoriedade (onde cada nova unidade de informação pode ser prevista pela anterior) (Gleick, 1990); e de fidedignidade (ou confiabilidade) - capacidade de resistir às perturbações aleatórias (ruído), que está relacionada às propriedades inerciais do sistema: quanto mais fidedigno, menor é a probabilidade de ocorrerem erros. Desta forma, a ordem de um sistema auto-organizado implica uma estruturação em patamares e depende de um jogo de interações entre o sistema e o meio. Relacionase ao caráter redundante $\mathrm{e}$ à fidedignidade deste sistema. Assim, a complexidade está indicada pelas seguintes características: grande variedade de elementos de diversas categorias, que possuem funçōes especializadas; organização destes elementos em niveis hierárquicos; multiplicidade de relações entre elementos e níveis (conectividade); interações entre os níveis que não seguem padrões lineares (Jacquard, 1988; Bourguignon, 1990). A auto-organização está relacionada ao fato do ruído (seja exógeno ou endógeno) elevar a quantidade de informação do sistema, ao mesmo tempo que esta é reduzida pelo acúmulo de erros. Para que haja equilíbrio, é preciso um determinado grau de complexidade, com redundância e fidedignidade (e sua relação) em níveis satisfatórios para o funcionamento compatível com a sobrevivência do ser vivo. Quando os estímulos aleatórios encontram uma estrutura com poder auto-organizador, ao invés de destruí-la, provocam mudanças no sentido de ampliar sua complexidade. Tais modificações implicam novas propriedades, não previstas em seus pormenores, de modo a propiciar uma autoprodução de significação e, simultaneamente, um certo grau de indeterminação (Bourguignon, 1990).

$\mathrm{Na}$ Epidemiologia, tal situação é discutida por Almeida Filho ao delinear as caracteristicas de uma nova configuração paradigmática, de modo a incluir a abordagem complexa do processo saúde/doença. Esta constituir-se-ia sob a égide de um paradigma - " 3 " - que superaria as limitações dos paradigmas "1" (da epidemiologia dos modos de transmissão) e " 2 " (da epidemiologia dos fatores de risco). Assim, ter-se-ia "um objeto-totalizado", "modelos de sistemas dinâmicos" (ou, melhor dizendo, instáveis) regidos por "interdeterminação" (sistemas de causação circular), descritos por "funções nãolineares" e representados graficamente por atratores (estranhos) (Almeida-Filho, 1990).

Nesta perspectiva, existem, nas Ciências Naturais, tentativas de mensurar a complexidade em sistemas evolutivos mediante modelos matemáticos. Tais procedimentos têm sido empregados com a finalidade básica de simular, na medida do possível, as circunstâncias de ocorrência dos fenômenos e, em função disto, prever o comportamento das variáveis de interesse.

O uso de modelagem em epidemiologia pode ser rastreado nos trabalhos de Sir Ronald Ross sobre a malária, através de sua teoria dos acontecimentos (Ross, 1910). Mais recentemente, surgiram na Epidemiologia tentativas de lidar com os já referidos problemas: a generalização dos achados de estudos amostrais (Miettinen, 1985) e os problemas das passagens entre diferentes níveis de organização (Susser, 1973), seja através da discussão metodológica relativa aos estudos ecológicos (Morgenstem, 1985; Piantadosi et al., 1988), seja mediante propostas de "modelização qualitativa" dos sistemas dinâmicos (Puccia \& Levins, 1985) ou a partir das elaborações matemáticas acerca (a) de acontecimentos dependentes (Halloran \& Struchiner, 1991); (b) dos estudos epidemiológicos baseados na teoria do caos (Olsen \& Schaffer, 1990); (c) da teoria da epigênese (patogênese epidemiológica) aplicada ao relacionamento da patogênese no indivíduo e aos padrões de doença em populações (Koopman \& Weed, 1990), entre outros.

Em geral, os estudos de doenças mediante modelagem matemática parecem ser úteis em determinadas situações nas quais têm-se o conhecimento (e controle) das variáveis intervenientes. Via de regra, os modelos estocásticos são considerados os mais apropriados para tal finalidade (Sanches, 1984). No entanto, o modelo precisa ser "calibrado" conforme cada contexto de aplicação para se verificar o grau de ajustamento à "realidade" que se propõe simular (Sanches, Comunicação Pessoal, 1992).

Por outro lado, é preciso levar em conta que, com frequiência, os processos biológicos assumem comportamentos cujas leis não são conhe- 
cidas, - sendo impossível determinar todas as variáveis intervenientes no sistema e suas intrincações. Sanches sublinha que a complexidade, nestas situações, decorreria da interação entre o pesquisador e o fenômeno estudado, resultante da abordagem mensuradora. Deste modo, seria possivel conceber patamares diferenciados de complexidade conforme a magnitude de tal interação (Sanches, 1984).

De qualquer maneira, a perspectiva de modelização dos sistemas dinâmicos concebe o objeto de estudo como sendo determinado por fatores que se modificam durante o próprio processo de determinação, de tal modo que os parâmetros sofrem variações no decorrer do evento (Almeida-Filho, 1992). Mas, neste ponto, cabe perguntar se esta via de modelização matemática de sistemas dinâmicos seria indiciária de propostas de avanço teórico no campo. Ou seja, estaria vinculada a um movimento de transformação da Epidemiologia, junto com a mudança do quadro epistêmico, diante da crise dos paradigmas científicos tradicionais e da emergência de novas questões pertinentes na especificidade histórica da nossa época? Ou, então, constituir-se-ia numa tentativa de sustentação do modelo racionalista de ciência, caudatário do empiricismo (enquanto mantenedor de cientificidade), que procura se legitimar mediante o panegírico do método e da sofisticação tecnológica no processamento da informação? Tais características no empreendimento investigativo foram levadas ao paroxismo na Epidemiologia, com a proliferação das técnicas de análise multivariada, e viabilizadas pelo grande acesso aos recursos computacionais. Como diz Susser - um insuspeito epidemiologista "tradicional" -, "as variáveis analisadas são múltiplas, mas estāo freqüentemente divorciadas tanto do substrato biológico como do contexto societário" (Susser, 1989: 481). Mesmo assim, nesta altura, ainda é prematura qualquer definição quanto ao significado promissor do emprego da modelagem matemática de sistemas dinâmicos, no sentido de viabilizar avanços na pesquisa epidemiológica com vistas a propor respostas mais resolutivas no que se refere à morbi-mortalidade no panorama da saúde contemporânea.

De qualquer forma, caso se reconheça a existência (ou a necessidade) de várias epide- miologias no lugar da abordagem epidemiológica tradicional, isto implica novos recortes que permitam individualizar, no interior de um mesmo quadro epistêmico, várias identidades especificas de cada disciplina epidemiológica, conforme o grau de desenvolvimento e aprofundamento alcançado em cada território. Como foi mencionado no início deste ensaio, há sinais de inquietação nas hostes epidemiológicas, sugerindo uma "crise na Epidemiologia" (AlmeidaFilho, 1992), que parecem apontar para esta situação de mutação. Só que a "consciência" da crise, o "mal-estar" que atinge o campo epidemiológico, pode ser visto como um efeito uma espécie de alter ego - que acompanha o otimismo tecnológico da cultura ocidental no momento da sua maior potência universalizante. Esta crise pode, portanto, ser entendida de duas maneiras interligadas: 1) como consciência da erosão interna e/ou externa dos fundamentos sobre os quais baseiam-se uma prática e um saber (nesta situação, a crise teria nascido com a consciência crítica, a "suspeita" e o "relativismo" do século $\mathrm{XX}$ ); ou 2) como complexificação dos pontos de vista sobre o real (pluralidade e complementaridade dos pontos de vista, interdisciplinaridade), isto é, como consciência da complexificação que transforma o quadro epistêmico tradicional. É esta "transformação" de todo o quadro epistêmico que caracteriza uma revolução científica e que envolve a "simples" mudança ou substituição de paradigmas. É por esta razão, pensamos, que o problema da complexidade não pode ser reduzido à emergência de um "paradigma da complexidade $^{\prime \prime}$ que tornar-se-ia dominante, pois trata-se de uma transformação mais radical da inteira Weltanschauung de uma época. Ou seja, a emergência de um "novo espírito científico" no interior de uma "nova visão de mundo", acoplada a um novo Zeitgeist, situação esta que demanda uma nova "síntese", a partir das interfaces das disciplinas existentes.

Esta exigência de "síntese" manifesta-se com particular insistência na necessidade da transdisciplinaridade, a qual se exprime cada vez mais nas ciências; na integração, por exemplo, entre modelos relativos a campos de investigação diferentes. Neste caso, a busca de analogias na explicação relaciona-se, necessariamente, com a aspiração em descobrir (ou, mais precisamen- 
te, em construir) a unidade na diversidade. No que diz respeito à inteligibilidade, esta depende da linguagem utilizada, ou seja, da condição de uma linguagem bem definida e de regras explicitáveis. É somente no sentido desta condição epistemológica, pensamos, que é possível falar em objetividade científica, e não no sentido ainda presente nas ciências, de "reflexo" do real pela teoria (representacionismo). Dito de outra maneira, se uma certa adequação "ao limite" entre real e conhecimento parece ineliminável do imaginário científico para evitar as construções mais arbitrárias, tal adequação, no entanto, não seria uma forma de representação do real pela teoria. A adequação seria mais do tipo "coerência" na construção de parâmetros, modelos ou teorias, e entidades significativas do real escolhidas, ou seja, na pertinência entre racionalidade interna construída na teoria e racionalidade externa suposta no real. Esta coerência é possível somente se as relações externas são semanticamente concebiveis, independentemente do grau de aproximação atingido. Em outras palavras, a objetividade seria, em primeiro lugar e racionalisticamente falando, uma explicitação semanticamente correta, e é neste sentido que podemos falar em construtivismo.

Mas, admitindo-se esta forma não-radical de construtivismo, coloca-se uma série de questões críticas fundamentais. A primeira e a mais geral: existe uma forma ideal (eficaz) de explicação dos fenômenos? A segunda, que é um desdobramento da primeira: se a resposta for sim, existe uma diferenciação mais precisa entre modelo e teoria que não a da menor ou maior abrangência cognoscente? No caso de uma resposta afirmativa, é possível um melhor equilíbrio entre modelo e teoria, entre explicação e compreensão? Seria pretensão nossa responder aqui diretamente a questões fundamentais que transcendem ao campo epidemiológico, pois são constitutivas do próprio fazer científico. Limitaremo-nos, portanto, a algumas considerações "preliminares".

Em primeiro lugar, se uma teoria ideal é aquela que tem uma certeza completa da validade dos seus princípios e esquemas explicativos (i.e., dos seus pontos de vista), ela estaria condenada a ser não falsificável; em termos popperianos, ela não seria propriamente científi- ca. Com efeito, a "incerteza" faz parte do Zeitgeist atual e afeta também o saber científico contemporâneo (considere-se só a importância da "teoria do erro" na Física), na medida em que todo ponto de vista, por mais complexo que ele se conceba, sempre é apenas um dispositivo que o sujeito cognoscente constrói para se aproximar do real, recriando-o e tornando-o inteligível o mais que se possa. Sem este dispositivo, o real não se dá ao sujeito, pois ele é suscetivel de ser conhecido por meio de uma série aberta de pontos de vista pertinentes para os sujeitos da prática cognoscente. Assim, se a ciência parece estar "condenada" à incerteza e à abertura - à precariedade e à falsificabilidade, como condições dos seus avanços - ela parece também ter que "se salvar" por meio da eficácia prática dos conhecimentos adquiridos, isto é, ela deve ser funcional. Todavia, o "destino" técnico-científico da procura da eficácia prática implica a existência contínua de conhecimentos empíricos mais eficazes, ou seja, melhores do próprio ponto de vista pragmático. De tal maneira, a redução pragmática da ciência submete esta a um processo "autofágico" de obsolescência.

Um outro caminho poderia ser a construção de dispositivos cognitivos mais coerentes do ponto vista lógico, como foi o caso das tentativas do empirismo lógico e, em geral, do racionalismo. Mas também este caminho tem uma limitação significativa, na medida em que escamoteia a questão da confrontação com o empírico.

No entanto, o que seria, de fato, uma explicação consistente que desse conta de fenómenos reais, em si independentes de um observador, mas acoplados a este no processo de conhecimento? Ela deveria ter alguma "conformidade" com o real para poder aprendê-lo? Dito de outra forma, como pode uma explicação ser verossímil? Esta "verossimilhança" pressupõe um conhecimento do tipo analógico que "asseguraria" melhor o real. A capacidade em estabelecer analogias constituiria, então, uma qualidade emergente da matéria viva e pensante que, ao se pensar, conseguiria estabelecer as relações significativas com o real, ao invés de se pensar como separada.

Um dos pensadores que mais contribuiu para a reformulação desta nova maneira de conceber 
as relações entre conhecimento e real foi $o$ antropólogo Gregory Bateson. Para este autor, qualquer definição dada é uma relação "construida" que está também inscrita no real que nós "representamos". Isto pressupõe que, na base de todo fenômeno, existe uma estrutura que conecta tal fenômeno com os outros (Bateson, 1972, 1979). O "tecido" constituído pelas "coisas vivas" seria fabricado pela mente não de maneira lógica, mas primordialmente de maneira analógica, ou, para utilizar os termos de Bateson, metaforicamente. No mundo da vida, existiriam sempre cadeias circulares de causas e efeitos (feedbacks), nas quais os efeitos tornam-se causas e, portanto, a metáfora estaria na base da vida como um tipo particular do relacionar-se. Assim, se a lógica constituiria um instrumento poderoso e "elegante" para descrever sistemas lineares de causas e efeitos, pouco importa se múltiplos, ela revelar-se-ia insuficiente para dar conta de sistemas circulares (como os sistemas vivos), pois geraria paradoxos de tipo lógico. $O$ traço fundamental deste "novo paradigma" consistiria, então, na passagem do enfoque estático e "representacionista" dos objetos para o enfoque "construtivista" das relações entre objetos que, como no caso dos seres vivos, são sempre relações dinâmicas e, em parte, imprevisíveis. Para Bateson, esta passagem dos "objetos" para as "relações" é uma condição necessária para toda análise dos seres vivos, porque a própria forma biológica compor-se-ia de relações, e não de partes. Em outras palavras, as relaçōes seriam uma peculiaridade de todo o mundo dos viventes e, dentro deste, existiria uma qualidade emergente e auto-reflexiva constituída pela própria "mente" ou "espírito", ou seja, a capacidade de construir relações de relações. Assim, para que se pudesse dizer algo de pertinente sobre aquilo que pertence à vida, seria indispensável utilizar uma linguagem que falasse de relações e não de objetos. Além disso, tais relações deveriam ser consideradas como dinâmicas, isto é, sujeitas ao tempo e à história. A própria causalidade deveria ser pensada de maneira dinâmica, pois a causa estaria sempre submetida à retroação do efeito. A estrutura da "natureza" e a da "mente" constituiria, então, uma unidade necessária (Bateson, 1979). Toda discussão sobre processos não poderia esquecer esta "complexidade" inscrita na própria vida que se pensa e que pensa que pensa, e toda modelização ou teorização estaria limitada pela própria obsolescência inelutável, devido às produçōes que mudam ao longo do tempo e da história e, a princípio, se aperfeiçoam. Todo modelo or teoria sobre aspectos da vida seria, então, um instrumento precário sobre um mundo ao mesmo tempo natural e histórico, em constante complexificação.

Entretanto, modelos e teorias são precários também de um outro ponto de vista, o qual chamaremos de antropológico e que concerne a dependência do homem da própria cultura, isto é, da sua inserção particular no quadro epistêmico do próprio tempo. Esta inserção é do tipo necessário, a tal ponto que o conhecimento produzido se torna uma espécie de verdadeira "segunda natureza", que garante a pertinência do conhecimento. Este fato, apontado por Geertz na Antropologia (Geertz, 1975), tem duas conseqüências pragmáticas importantes na nossa discussão. Em primeiro lugar, porque modelos e teorias parecem ser tanto mais eficientes quanto mais "naturalizados, isto é, eficazes, na medida em que são tidos como "reflexos" da própria realidade, conseqüências do próprio objeto, e não construçōes de um sujeito em interação com um ambiente ao qual ele pertence enquanto sistema. A longa estação do empirismo nas ciências provavelmente tem a ver com a resistência deste tipo de naturalização. Em segundo lugar, a utilização de modelos e teorias na prática científica transforma-os em função do princípio da "melhor performatividade" na abordagem do real (Lyotard, 1979). Assim, modelos e teorias se diferenciam, entram em crise, tornam-se obsoletos e criam as condições para a emergência de outros pontos de vista, de outros paradigmas (Kuhn, 1975).

Desta maneira, modelos e teorias estão submetidos a um movimento aparentemente contraditório de conservação (devido ao poder de "naturalização") e de transformação (por causa da lei da "performatividade"), fato que lhes confere um estatuto, por assim dizer, "parado$\mathrm{xal}^{\prime \prime}$. Com efeito, se, por um lado, eles precisam de uma certa estabilidade para que possam ser utilizados (e a dificuldade de se pensar em termos "dinâmicos" ilustraria esta resistência), por outro lado, eles estão submetidos à lógica 
implacável da obsolescência pelo próprio fato da evolução do conhecimento, pela emergência de novos pontos de vista e de novas necessidades práticas. Assim, a precariedade de modelos e teorias aparece no exato momento em que estes são testados. E não poderia ser diferente, pois, para serem produtivos, ou "vivos" (o próprio Bateson, entre outros, fala em "vida" das idéias), modelos e teorias devem se submeter às necessárias transformaçōes requeridas pela integração de novos pontos de vista e de novas exigências pragmáticas.

\section{PARA NÃO CONCLUIR}

Em resumo, encaramos a "crise" da Epidemiologia como uma "crise" que atinge praticamente o inteiro edifício do saber. Entretanto, é possivel supor que, devido aos novos desafios para a Saúde Pública, combinados aos velhos problemas ainda não resolvidos, a "crise da epidemiologia" seja, de fato, uma crise de "crescimento" ou de complexificação que, juntando o velho ao novo, configura um novo universo prático-discursivo sobre saúde/doença. Alguns epistemólogos contemporâneos qualificam esta nova situação como um desafio da complexidade (Bocchi \& Ceruti, 1987), ou seja, como uma situação em que existe a necessidade de se pensar e agir não em termos de objetos, mas em termos de relações. Assim, o "complexo" seria, literalmente, a marca de "aquilo que está junto", como é o caso dos organismos vivos, dos grupos, das populações, do ambiente.

Contudo, quando se fala, hoje, em "paradigma da complexidade", comete-se um abuso epistemológico reduzindo-se a Weltanschauung e o Zeitgeist da complexidade a um simples paradigma. Como afirma a epistemóloga Isabelle Stengers, a complexidade "não se refere a uma disciplina especifica nem a um conjunto de técnicas suscetiveis de resolver classes de problemas definidos, [ela representa o] despertar para um problema, uma tomada de consciência (...) expressa de modo não somente intelectual, como também ético" (Bocchi \& Ceruti, 1987: 61). É nesta junção entre "estético" e "ético" que o "desafio da complexidade" corresponde a uma "gênese conceitual" (Sten- gers, 1990), à mudança do ponto de vista sobre o padrão que une (Bateson, 1979), isto é, a um novo enfoque sobre a própria vida. Porém, se a descoberta do desafio da complexidade impõe uma "nova relação de conhecimento", assim como um novo enfoque das relações éticas, ela não pode, no entanto, ser tida como "uma panacéia universal, [pois ela constitui] a descoberta de problemas, mais do que de soluçōes" (Stengers, 1990: 80).

Neste sentido, a "crise" da Epidemiologia seria uma crise especifica da insuficiência de parte dos seus próprios instrumentos, que se tornam inevitavelmente obsoletos (os esforços recentes de produção de novas abordagens, citadas anteriormente, apontam, inevitavelmente, para a admissão deste problema) devido à emergência de novos desafios externos para a saúde individual e coletiva que se juntam aos antigos desafios não resolvidos. $\mathrm{E}$, também, trata-se de uma crise de crescimento interno à disciplina, devido às novas "bricolagens" (como diria Lévi-Strauss) que necessariamente são pensadas e feitas para sustentar tais desafios, tentando, apesar de tudo, recuperar, na complexidade crescente do mundo atual, algo parecido com o exercicio racional da previsão, consciente da incerteza que necessariamente a desafia.

\section{AGRADECIMENTOS}

Queremos agradecer aos consultores pelo empenho e pertinência de seus comentários. Uma menção especial ao Prof. C. J. Struchiner, que enriqueceu muito o artigo com seus aportes e detalhadas indicações bibliográficas.

\section{RESUMO}

SCHRAMM, F. R. \& CASTIEL, L. D. Processo Saúde/Doença e Complexidade em Epidemiologia. Cad. Saúde Públ., Rio de Janeiro, 8 (4): 379-390, out/dez, 1992.

O emprego da idéia de complexidade em epidemiologia serve para assinalar as crises, tanto no domínio interno da disciplina resultante de uma cada vez mais evidente limitação de seus instrumentos conceituais 
(modelos e teorias) para lidar com a realidade concreta da saúde - como no domínio do contexto cultural (paradigmas, quadro epistêmico, Zeitgeist, Weltanschauung) no qual os problemas de saúde estão inscritos. Apesar de ambas as abordagens serem pertinentes, sob a ótica do sistema e do ambiente, sua separação leva a uma apreensão restrita dos atuais desafios no campo sanitário, $e$, portanto, insuficiente para promover a saúde e o bem-estar de indivíduos, populações e biosfera. A idéia de complexidade propõe-se a ultrapassar esta precariedade, apontando o reducionismo das dicotomias oriundas da era moderna, que tende a não estar equipado para perceber o universo composto por relações e emergências de novas propriedades ao se transitar por níveis diferenciados de organização. Além disso, discute modos de encarar os processos que ocorrem entre os seres vivos de maneira a incluir dimensões dinâmicas, evolutivas e históricas. Assim, há indícios de crise da Epidemiologia que apontam para a necessidade da complexificação de seus instrumentos práticodiscursivos, de forma a viabilizar construções mais satisfatórias do processo saúde-doença.

Palavras-Chave: Epidemiologia, Epistemologia, Complexidade

\section{REFERÊNCIAS BIBLIOGRÁFICAS}

ALMEIDA-FILHO, N., 1989. Epidemiologia sem Números; uma Introdução Critica à Ciência Epidemiológica. 108 p., Rio de Janeiro: Campus. , 1990. Paradigmas em epidemiologia. Anais do $1^{\circ}$ Congresso Brasileiro de Epidemiologia, Rio de Janeiro: Abrasco.

, 1992. A Clínica e a Epidemiologia. 164 p., Rio de Janeiro: Apce/Abrasco.

BACHELARD, G., 1985. O Novo Espirito Cientifico. Rio de Janeiro: Tempo Brasileiro.

BATESON, G., 1972. Steps to an Ecology of Mind. New York: Ballantine. , 1979. Mind and Nature. A Necessary Unity. New York: Dutton.

BOCCHI, G. \& CERUTI, R., 1987. La sfida della Complessità. Milano: Feltrinelli.

BOURGUIGNON, A., 1990. História Natural do Homem 1. O Homem Imprevisto. Rio de Janeiro: Zahar.
CASTELlanOS, P., 1990. Avanços Metodológicos en Epidemiologia. Anais do 1ํㅡㄹ Congresso Brasileiro de Epidemiologia, Rio de Janeiro: Abrasco.

CASTIEL, L. D., 1992. O Estresse na Pesquisa Epidemiológica: $O$ desgaste dos modelos de explicação coletiva do processo Saúde/Dıença. Physis, 2.

FEINSTEIN, A., 1989. Epidemiologic analyses of causation: the unlearned scientific lessons of randomized trials. Journal of Clinical Epidemiology, 42: 481-489.

FERRATER MORA, J., 1985. Diccionário de Filosofia. Madrid: Aliança Editorial.

GARCIA, J. C., 1983. Medicina e Sociedade: as correntes do pensamento no campo da Saúde In: Medicina Social: Aspectos Históricos e Teóricos (E. O. Nunes, org.), São Paulo: Global.

GEERTZ, C., 1975. The Interpretation of Cultures. London: Hutchinson.

GLEICK, J., 1990. Caos - A Criação de uma Nova Ciência. Rio de Janeiro: Campus.

GONÇALVES, R. B. M., 1990. Contribuição à discussão sobre as relações entre teoria, objeto e método em epidemiologia. Anais do $1^{\circ}$ Congresso Brasileiro de Epidemiologia, Rio de Janeiro: Abrasco.

HALLORAN, E. \& STRUCHINER, C. J., 1991. Study designs for dependent happenings. Epidemiology, 2: 331-338.

JACQUARD, A., 1987. A Herança da Liberdade. Da Animalidade à Humanitude. Lisboa: Dom Quixote.

KOOPMAN, J. \& WEED, D., 1990. Epigenesis theory: a mathematical model relating causal concepts of pathogenesis in individuals to disease patterns in populations. American Journal of Epidemiology, 132: 366-390.

KUHN, T., 1975. A Estrutura das Revoluçōes Científicas. São Paulo: Perspectiva.

LYOTARD. J. F., 1979. La Condition Postmoderne. Paris: Minuit.

MIETTINEN, O., 1985. Theoretical Epidemiology Principles of Occurrence Research in Medicine. New York: John Wiley \& Sons.

MORGENSTERN, H., 1982. Uses of ecologic analysis in epidemiologic research. American Journal of Public Health, 127: 893-904.

MORIN, E., 1986. La Méthode. La Connaissance de la Connaissance. Paris. Seuil.

NICOLIS, G. \& PRIGOGINE, I., 1991. La Complessitc̀ Esplorazioni dei Nuovi Confini della Scien$z a$. Torino: Einaudi.

OLSEN, L. F. \& SCHAFFER W. M., 1990. Chaos versus noisy periodicity: alternative hypotheses for childhood epidemics. Science, 249: 499-504. 
ORTEGA Y GASSET, J., 1984. Qué es Conocimiento? Madrid: Aliança Editorial.

PIAGET, J., 1937. La Construction du Réel Chez l'Enfant. Neuchâtel: Delachaux \& Niestlé.

PIAGET, J. \& GARCIA, R., 1987. Psicogênese $e$ História das Ciências. Lisboa: Dom Quixote.

PIANTADOSI, S.; BYAR, D. P. \& GREEN, S. B., 1988. The ecological fallacy. American Journal of Epidemiology, 127: 893-904.

POSSAS, C., 1990. Perspectivas para a ciência epidemiológica numa abordagem interdisciplinar. Anais do $1^{\circ}$ Congresso Brasileiro de Epidemiologia, Rio de Janeiro: Abrasco.

PRIGOGINE, I. \& STENGERS, I., 1979. La Nouvelle Alliance. Métamorphoses de la Science. Paris: Gallimard.

PUCCIA, C. J. \& LEVINS, R., 1985. Qualitative Modeling of Complex Systems: An Introduction to Loop Analysis and Time Averaging. Cambridge: Harvard University Press.

RODRIGUES DA SILVA, G., 1990. Avaliação e Perspectivas da Epidemiologia no Brasil. Anais do $1^{\circ}$ Congresso Brasileiro de Epidemiologia, Rio de Janeiro: Abrasco.
ROSE, G., 1985. Individuos Enfermos y Poblaciones Enfermas. Boletín Epidemiológico de la Organización Panamericana de la Salud, 6: 13-19.

ROSS, R., 1910. The Prevention of Malaria. $2^{\text {nd }}$ ed., New York: E. P. Dutton.

SANCHES, O., 1984. Considerações sobre modelos matemáticos em doenças transmissíveis. Ciência e Cultura, 36: 545-549.

STENGERS, 1., 1990: Quem tem Medo da Ciência? Ciências e Poderes. São Paulo: Siciliano.

SUSSER, M., 1973. Causal Thinking in the Health Sciences. London: Oxford University Press.

, 1989. Epidemiology Today: "A Thought-Tormented World". International Journal of Epidemiology, 18: 481-488.

, 1991 . What is a cause and how do we know one: a grammar for pragmatic epidemiology. American Journal of Epidemiology, 133: 635-648. 